\title{
Article \\ The Tribological Performance of Metal-/Resin-Impregnated Graphite under Harsh Condition
}

\author{
Jun Zhao ${ }^{1,2,3} \mathbb{D}^{D}$, Yijiang Liu ${ }^{1}$, Dengyu Liu ${ }^{1}$, Yanfei Gu ${ }^{1}$, Rao Zheng ${ }^{1}$, Runmei Ma ${ }^{1}$, Shuangxi Li ${ }^{1, *}$, \\ Yongfu Wang ${ }^{4, *}$ and Yijun Shi ${ }^{3}$ D
}

1 College of Mechanical and Electrical Engineering, Beijing University of Chemical Technology, Beijing 100029, China; zhaojun@mail.buct.edu.cn (J.Z.); YJLiu1024@163.com (Y.L.); liudengyu163@163.com (D.L.); 13269663366@163.com (Y.G.); zhengrao@mail.buct.edu.cn (R.Z.); marm@mail.buct.edu.cn (R.M.)

2 State Key Laboratory of Organic-Inorganic Composites, Beijing University of Chemical Technology, Beijing 100029, China

3 Division of Machine Elements, Luleå University of Technology, 97187 Luleå, Sweden; yijun.shi@ltu.se

4 State Key Laboratory of Solid Lubrication, Lanzhou Institute of Chemical Physics, Chinese Academy of Sciences, Lanzhou 730000, China

* Correspondence: buctlsx@126.com (S.L.); yongfuwang@licp.cas.cn (Y.W.)

check for updates

Citation: Zhao, J.; Liu, Y.; Liu, D.; Gu, Y.; Zheng, R.; Ma, R.; Li, S.; Wang, Y.; Shi, Y. The Tribological Performance of Metal-/Resin-Impregnated Graphite under Harsh Condition. Lubricants 2022, 10, 2. https:// doi.org/10.3390/lubricants10010002

Received: 11 November 2021

Accepted: 18 December 2021

Published: 22 December 2021

Publisher's Note: MDPI stays neutral with regard to jurisdictional claims in published maps and institutional affiliations.

Copyright: (C) 2021 by the authors. Licensee MDPI, Basel, Switzerland. This article is an open access article distributed under the terms and conditions of the Creative Commons Attribution (CC BY) license (https:// creativecommons.org/licenses/by/ $4.0 /)$.

\begin{abstract}
Graphite-based composites are well recognized as ideal functional materials in mechanical seals, bearings of canned pumps, and electrical contact systems because of their outstanding selflubricating ability, thermostability, and chemical stability. Working in harsh conditions is a huge challenge for the graphite materials, and their tribological properties and wear mechanisms are not well studied. In this study, the tribological performance of metal-impregnated graphite, resinimpregnated graphite, and non-metal-impregnated graphite under high temperature and high load are studied using a ball-on-disc tribometer. The results show that the metal-impregnated graphite (Metal-IG) has a stable friction regime and exhibits better anti-friction and anti-wear properties than that of resin-impregnated graphite (Resin-IG) and non-impregnated graphite (Non-IG) under extreme pressure (200 350 MPa) and high temperature $\left(100-350{ }^{\circ} \mathrm{C}\right)$. The Metal-IG and Resin-IG can reduce the wear depth by $60 \%$ and $80 \%$, respectively, when compared with Non-IG substrate. The impregnated materials (metal or resin) can enhance the strength of the graphite matrix and improve the formation of graphite tribofilm on the counterpart surfaces. Friction-induced structural ordering of graphite and slight oxidation of metal in the formed mechanically mixed layer is also beneficial for friction and wear reduction. This study demonstrates the tribological characteristics of impregnated graphite under harsh conditions and provides the experimental basis for the advanced usage of high-reliability and self-lubrication graphite composites.
\end{abstract}

Keywords: friction; wear; impregnated graphite; high load; high temperature

\section{Introduction}

With the development of industry, much advanced mechanical equipment is required to effectively operate under harsh environments such as high temperature, high load, and high speed in the fields of aerospace engineering, ocean engineering, and equipment manufacturing. It is obvious that the significant energy wastage and material losses result from friction and wear [1-4]. Graphite-based materials are often used in this field due to their outstanding abilities of self-lubrication, heat transfer, and corrosion resistance [5-7]. In general, there are some structural defects in the graphite matrixes coming from manufacturing processes [8], which seriously affect their mechanical strengths and tribological performance. Vacuum impregnation of metals and resins in graphite is one efficient way to improve its mechanical and tribological performances [9-16].

There are two main kinds of impregnated composites, including metal-impregnated graphite and resin-impregnated graphite. Lafon-Placette et al. [11] studied the tribological performances of the graphite composites impregnated by polyester and antimony. They 
showed that both polyester and antimony could improve the tribological properties of graphite materials. Copper impregnating to graphite could be used for the enhancement of graphite [17-23]. The copper-impregnated graphite shows good anti-friction and antiwear performance when rubbing against stainless steel [9]. Inspired by the ability of soft metals to enhance the tribological properties of graphite, many researchers used resin materials with enhanced fluidity to reinforce the graphite matrix $[10,12,15]$. The phenolic resin was widely used to impregnate the graphite matrix, and the progressive relationship between the coefficient of friction (COF) and the resin component was also revealed [15]. Resin-impregnated graphite and non-impregnated graphite were compared under different friction conditions by Zhang et al. [13]. It was found that the resin impregnation enhanced the mechanical properties of graphite, which led to a lower fraction of open pores, then reduced the friction between the friction pairs. Zhu et al. [14] found the furan resinimpregnated graphite composite had much better mechanical and tribological properties compared with the non-impregnated graphite. Vespel polyimide impregnated graphite was utilized for the application of mechanical seals [17], which could improve wear resistance and reduce torque loss.

Apart from the physical and chemical characteristics of graphite composites, the friction conditions have a huge influence on their tribological properties. Under dry friction, the graphite tends to be transferred to the rubbing surface and reduces the direct contact between the friction pairs [24-27]. The COF of the graphite is lower under water or oil lubrication than that under dry conditions [28-31]. Because the liquid constrained between friction interfaces sustains a high pressure and generates hydrodynamic lubrication, however, lubricants hindered the formation of a graphite transfer film on the counterpart [13]. Guo et al. [29] studied cemented carbide sliding against graphite under water conditions, and an ultralow COF was achieved. Cui et al. [30] studied the tribological properties of graphite/cemented carbide under seawater. Although seawater can also improve interfacial lubrication, it would result in electrochemical corrosion of rubbing surfaces. In addition, the sliding velocity, load, and temperature have prominent effects on the tribological properties of impregnated graphite. With an increase in the velocity, the COF gradually decreases $[13,26]$. Conversely, the COF has a positive correlation with the normal load [7,14]. Our previous work found that high temperature can improve the tribofilm formation of the resin-impregnated graphite materials, thus they have good tribological properties at a higher temperature [32]. Working in harsh conditions is a huge challenge for graphite materials. Graphite composites are mainly studied under normal load and temperature $[10,18,19]$, which are difficult to meet the requirement of actual application. For example, the harsh contact load of mechanical seals is as high as 100 250 MPa [33]. However, few studies focused on their tribological properties under harsh friction conditions (200 350 MPa and $\left.100-500{ }^{\circ} \mathrm{C}\right)$, and their tribological properties and wear mechanisms are not well investigated.

This study intends to investigate the tribological characteristics of typical impregnated graphite composites under harsh friction conditions (high temperature and high load). The purpose of this study is to understand the performance difference between metalimpregnated graphite and resin-impregnated graphite. The friction mechanisms of the graphite composites will be revealed by a scanning electron microscope (SEM), a Raman spectrometer, and an X-ray photoelectron spectroscope (XPS).

\section{Experimental Process}

\subsection{Materials}

In this study, the antimony metal-impregnated graphite (Metal-IG), furan resinimpregnated graphite (Resin-IG), and non-impregnated graphite (Non-IG) were provided by Shanghai Morgan Advanced Materials Co., Ltd. (Shanghai, China). The diameter of the disk is $24 \mathrm{~mm}$ and the thickness is $8 \mathrm{~mm}$, as shown in Figure 1c. Before the tests, the graphite surfaces are polished by a brass lapping machine. The surface roughness of the graphite materials is shown in Table 1. The microhardness is measured by a micro- 
hardness tester, the test load is $50 \mathrm{~g}$, and time of the process is $5 \mathrm{~s}$. The microhardness of metal-impregnated graphite is $340.38 \mathrm{HV}$, whereas those of resin-impregnated graphite and non-impregnated graphite are $123.44 \mathrm{HV}$ and $93.68 \mathrm{HV}$, respectively. The counterparts are steel balls purchased from Shanghai Steel Ball Plant Co., Ltd. (Shanghai, China). The diameter of the balls is $10 \mathrm{~mm}$, as shown in Figure 1b. The main physical parameters of these materials are listed in Table 1 . The steel balls and graphite samples are cleaned by alcohol in an ultrasonic cleaner for $30 \mathrm{~min}$, followed by drying process.
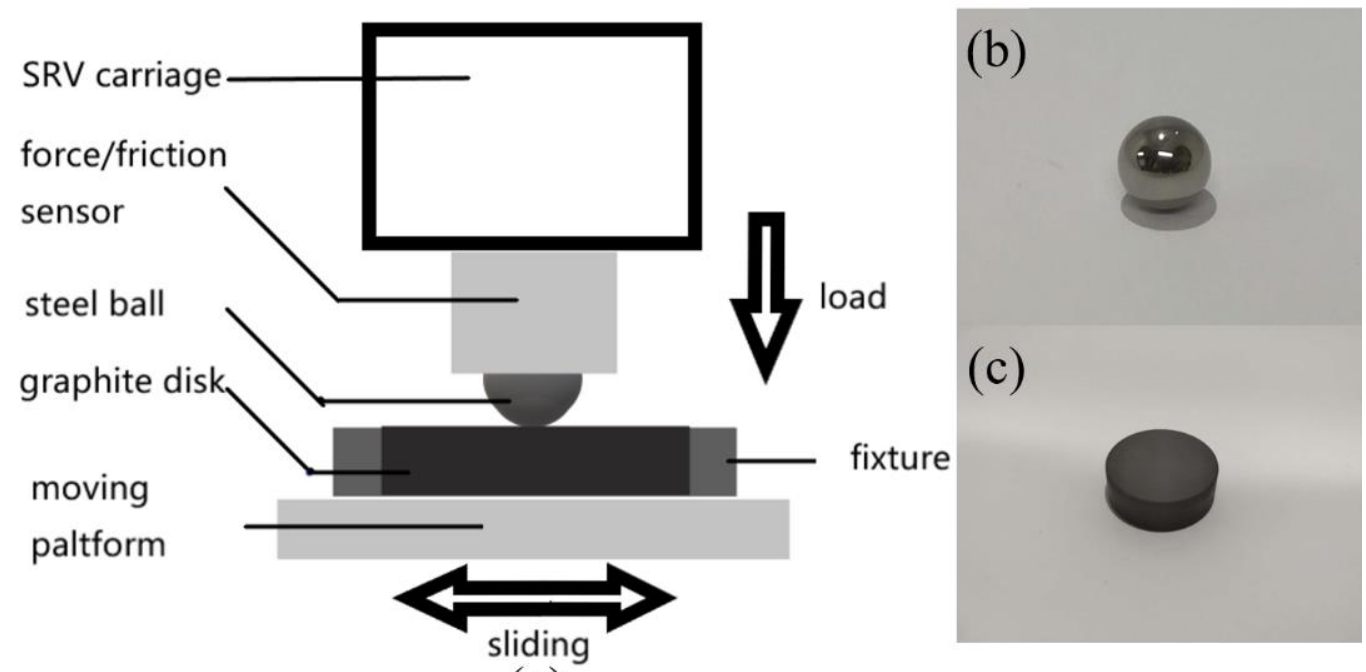

(a)

Figure 1. Schematic illustration of sliding friction test (a), optical topographies of steel ball (b), and impregnated graphite material disk (c).

Table 1. Mechanical and physical parameters of test materials.

\begin{tabular}{ccccc}
\hline Materials & Roughness (nm) & Microhardness & Density (g/cm $\mathbf{c m}^{\mathbf{3}}$ & $\begin{array}{c}\text { Open Porosity } \\
\text { (vol.\%) }\end{array}$ \\
\hline Metal-IG & 52 & $340.38 \mathrm{HV}$ & 5.58 & - \\
Resin-IG & 50 & $123.44 \mathrm{HV}$ & 1.83 & - \\
Non-IG & 55 & $93.68 \mathrm{HV}$ & 1.77 & 15 \\
Steel & 12 & $800 \mathrm{HV}$ & 7.90 & - \\
\hline
\end{tabular}

\subsection{Tribological Tests}

The tribological tests were carried out on a ball-on-disc test rig under reciprocating motion (SRV-4, München, Germany). Each test was repeated three times. Different disks of graphite composites (approximately $25 \mathrm{wt}$ \% of resin and metal) [15] were kept statically in place by the fixture of the tester. The schematic diagram of the test is illustrated in Figure 1a. The friction ball slid on the surface of the graphite disk. The reciprocating stroke was $2 \mathrm{~mm}$, and the sliding frequency was $10 \mathrm{~Hz}$. In particular, this study mainly focused on the friction characteristics of graphite under the harsh conditions of high temperature and high load for dry conditions, so the temperature varied from $25^{\circ} \mathrm{C}$ to $350{ }^{\circ} \mathrm{C}$ and the load was in the range of $20 \mathrm{~N}$ to $140 \mathrm{~N}$. The instantaneous Hertzian stress was $20 \mathrm{~N}(190.7 \mathrm{MPa}), 60 \mathrm{~N}$ (275 MPa), $100 \mathrm{~N}$ (325.9 MPa), and $140 \mathrm{~N}$ (364.6 MPa). The experimental parameters used in this study are shown in Table 2. 
Table 2. Experimental conditions and parameters used in this study.

\begin{tabular}{cc}
\hline Experimental Conditions & Parameter \\
\hline Temperature & $25-350{ }^{\circ} \mathrm{C}$ \\
Sliding Frequency & $10 \mathrm{~Hz}$ \\
Sliding Stroke & $2 \mathrm{~mm}$ \\
Friction Load & $20-140 \mathrm{~N}$ \\
Friction Time & $30 \mathrm{~min}$ \\
\hline
\end{tabular}

\subsection{Characterization}

The morphologies of initial surfaces and wear tracks were observed by an optical microscope (OM, Schneider Electric, Rueil, France). The microstructural characterization of worn surfaces was performed with scanning electron microscopy (SEM, JSM-5600 LV) with a secondary electron condition, and an accelerating voltage of $5 \mathrm{kV}$. A Raman spectrometer with $532 \mathrm{~nm}$ laser excitation was used to measure the Raman spectra of the graphite materials. In addition, the wear scar and the transfer film were characterized by Energy Dispersive Spectroscopy (EDS) with an accelerating voltage of $5 \mathrm{kV}$ and an X-ray photoelectron spectroscope (XPS, Thermo Fisher Scientific, Waltham, USA) operating with Al-K radiation.

\section{Tribological Results}

\subsection{Anti-Friction Properties}

The friction properties of Metal-IG, Resin-IG, and Non-IG are shown in Figure 2. At $25{ }^{\circ} \mathrm{C}$ (Figure 2a), the COF of Metal-IG is much lower than that of Resin-IG and NonIG, which means that Metal -IG has better anti-friction properties. The average COF values of the Metal-IG and the Resin-IG are approximately 0.165 and 0.183 , respectively. For comparison, the anti-friction property of Non-IG is unstable and its COF increases obviously with the increase in friction time [14]. At high temperature $\left(350{ }^{\circ} \mathrm{C}\right)$ (Figure $\left.2 \mathrm{~b}\right)$, the COF of Metal-IG and Resin-IG is decreased to 0.100 and 0.150 , respectively, at the beginning of the slide, and then increases obviously. For the Resin-IG, the anti-friction property deteriorates after a sliding time of $900 \mathrm{~s}$, and then the COF of the Resin-IG is as high as that of the Non-IG, which means Resin-IG has anti-friction properties under high temperature. In Figure 2c, the COF of Metal-IG is much more stable than other graphite samples at various temperatures, and the COF value is the lowest among the three materials. The average COF values of Resin-IG and Non-IG increase obviously with the increase in friction temperature. Hence, Metal-IG has better anti-friction property than Resin-IG and Non-IG.

As shown in Figure 2d, compared with Non-IG, Metal-IG and Resin-IG show much better anti-friction properties under each applied load. Non-IG and Resin-IG with poor mechanical performance would be crushed at a higher load of $100 \mathrm{~N}$ (average contact pressure is $325.9 \mathrm{MPa}$ ), and the friction sliding has to be terminated. Figure 2e shows the COF value of Resin-IG under a load of $100 \mathrm{~N}$. After a transient friction process, the value increases rapidly, meaning the anti-friction property is lost. High load of $100 \mathrm{~N}$ also crushes down resin-impregnated graphite. For comparison, the Metal-IG has excellent anti-friction properties even under high applied loads, as shown in Figure $2 \mathrm{f}$. It can be seen that there are two friction processes of run-in stage and working stage for Metal-IG. The COF fluctuates inevitably at the run-in stage, and then becomes smooth at the working stage. 

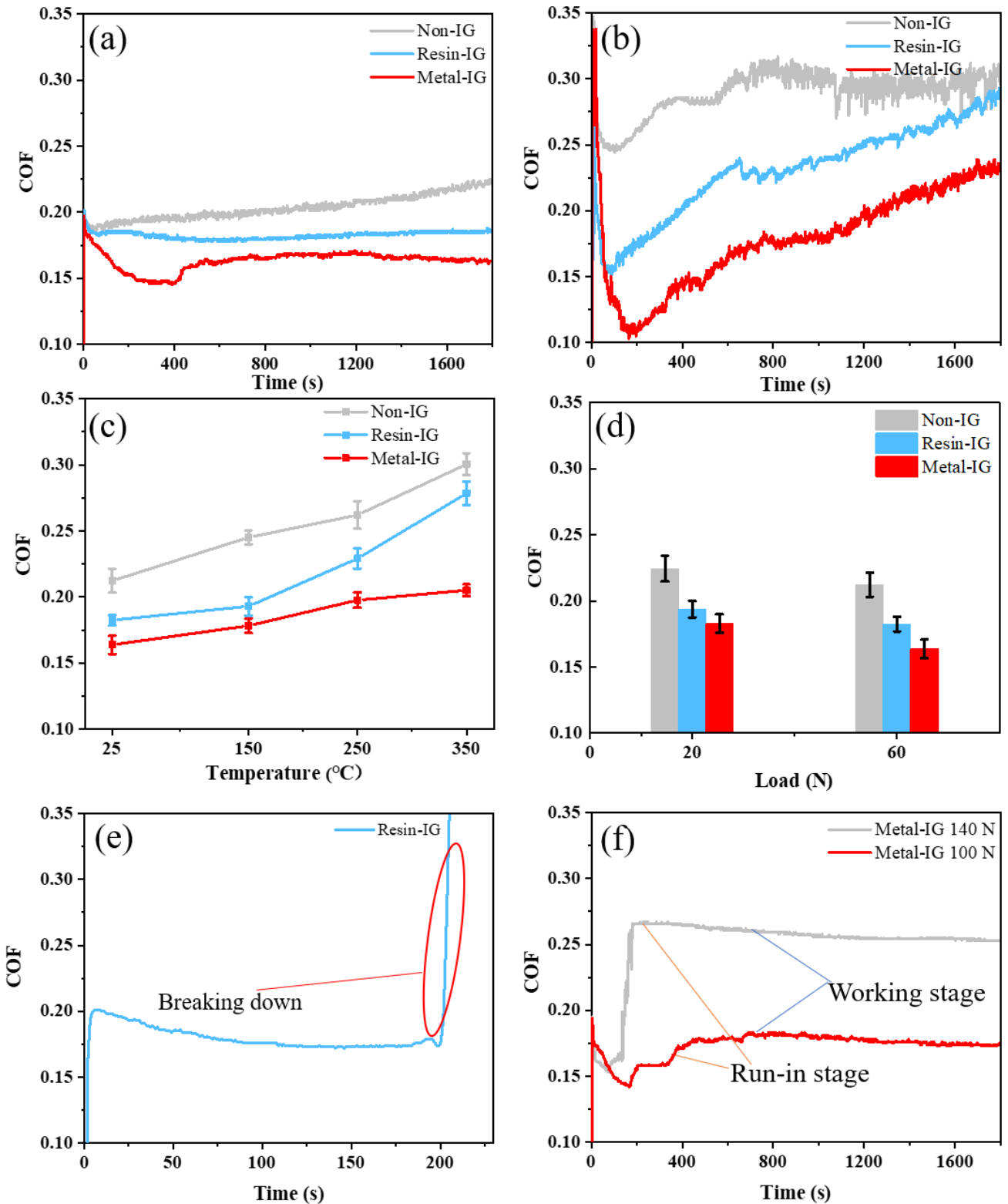

Figure 2. COFs of Metal-IG, Resin-IG, Non-IG under a load of $60 \mathrm{~N}$ at $25^{\circ} \mathrm{C}(\mathbf{a})$ and $350{ }^{\circ} \mathrm{C} \mathrm{(b)}$. COFs as a function of temperature under a load of $60 \mathrm{~N}$ (c), COFs under a load of $20 \mathrm{~N}$ and $60 \mathrm{~N}$ at $25^{\circ} \mathrm{C}$ (d). COFs of Resin-IG under a load of $100 \mathrm{~N}$ (e). COF of Metal-IG under a load of $100 \mathrm{~N}$ and $140 \mathrm{~N}$ (f).

\subsection{Anti-Wear Properties}

The wear tracks of Metal-IG, Resin-IG, and Non-IG are subsequently measured by an optical microscope and a white-light interferometer. As shown in Figure 3a,b, the wear depth and wear width of the impregnated graphite composites (Metal-IG and Resin-IG) are much lower than that of Non-IG at both $20 \mathrm{~N}$ (190.7 MPa) and $60 \mathrm{~N}$ (275 MPa). The worn wear surfaces of the Resin-IG result from the adhesive and abrasive wear behaviors, and there is a large wear depth because of abrasive debris worn out from the rubbing surface. The wear mechanism of the Metal-IG is adhesive wear without much abrasive process. Some worn-out debris from adhesive wear have good ductility and may accumulate at the boundary of the wear track and lead to a little higher width of the Metal-IG compared with the Resin-IG. Although the Metal-IG has better anti-friction properties than those of Resin-IG and Non-IG under high loads, the wear of Metal-IG becomes severe when the load increases to $140 \mathrm{~N}$, as shown in Figure 3c. The wear depth and wear width of Metal-IG increase when the applied load increases from $20 \mathrm{~N}$ to $140 \mathrm{~N}$. The wear depth and wear 
width of the all graphite materials are higher at the temperature of $150{ }^{\circ} \mathrm{C}$ than those at $25^{\circ} \mathrm{C}$. In contrast with Resin-IG and Non-IG, the anti-wear property of Metal-IG is much better at higher temperatures $\left(250^{\circ} \mathrm{C}\right.$ and $\left.350^{\circ} \mathrm{C}\right)$.
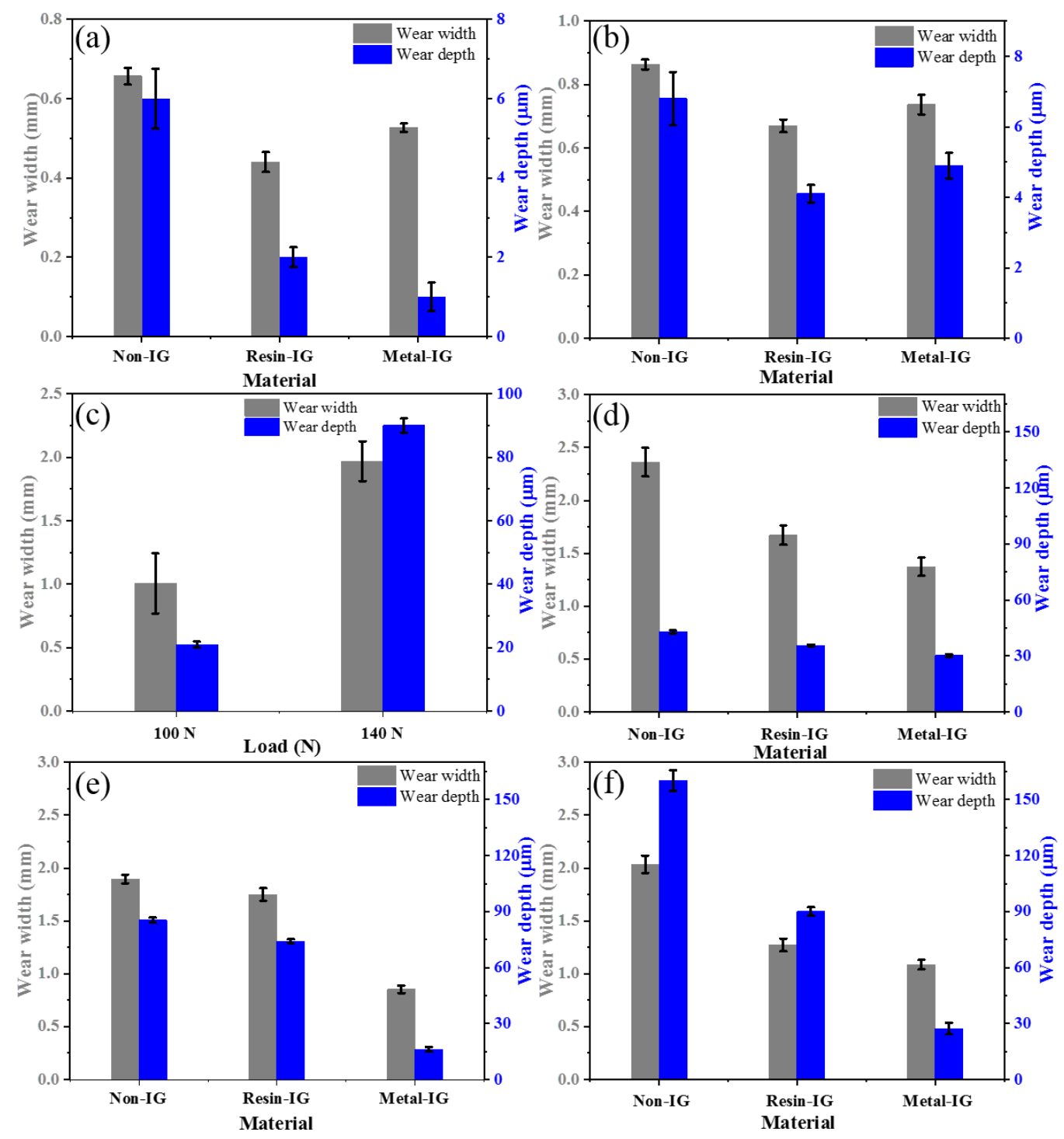

Figure 3. Wear width and depth of Non-IG, Resin-IG, and Metal-IG under a load of $20 \mathrm{~N}$ (a) and $60 \mathrm{~N}$ (b) at $25^{\circ} \mathrm{C}$. Wear width and depth of Metal-IG under a load of $100 \mathrm{~N}$ and $140 \mathrm{~N}$ at $25^{\circ} \mathrm{C}$ (c). Wear width and depth of Non-IG, Resin-IG, and Metal-IG at a load of $60 \mathrm{~N}$, at $150^{\circ} \mathrm{C}(\mathbf{d}), 250{ }^{\circ} \mathrm{C}(\mathbf{e})$, and $350{ }^{\circ} \mathrm{C}(\mathbf{f})$.

According to the optical micrographs and cross sections of wear tracks displayed in Figure 4, the rubbing surfaces of both metal- and resin-impregnated graphite are very narrow and smooth, whereas those of Non-IG display shallow grooves and wide furrows. This implies that the impregnation of resin and metal enhances the anti-wear properties of graphite. At low friction temperatures, the Resin-IG has good anti-wear properties. The above discussion agrees with the results of the wear width and wear depth in Figure 3. There exists obvious material rupture and wear ripples owing to the high pressures shown in Figure 5. In addition, the corresponding diameter of the Hertzian contact is approximately $266 \mu \mathrm{m}$ at the load of $60 \mathrm{~N}$. As shown in Figure 3, the diameter of the wear scar is far more than the value calculated, because under such high contact pressure (190.7 MPa, $275 \mathrm{MPa}$ at a load of $20 \mathrm{~N}, 60 \mathrm{~N}$ ), the graphite suffers severe wear. 


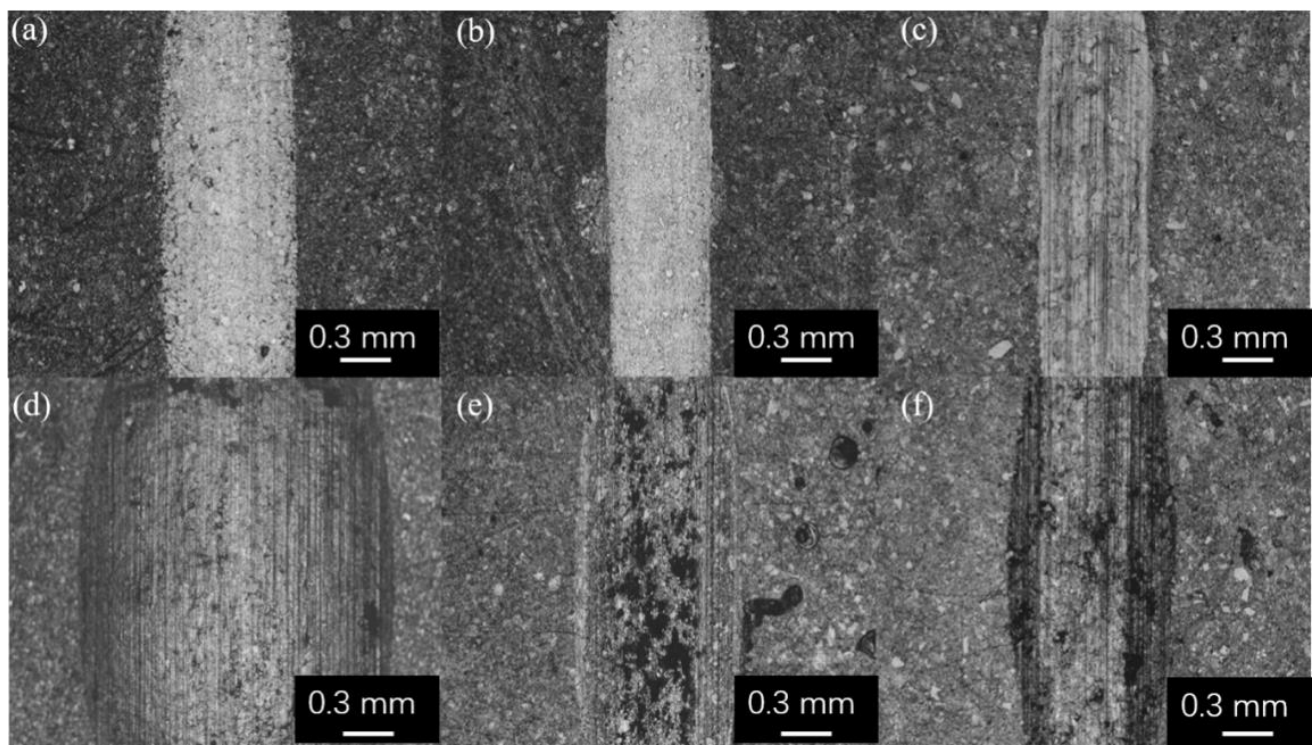

Figure 4. Optical micrographs of wear tracks of Non-IG (a), Resin-IG (b), and Metal-IG (c) under a load of $60 \mathrm{~N}$ at $25^{\circ} \mathrm{C}$. The wear tracks of Non-IG (d), Resin-IG (e), and Metal-IG (f) under a load of $60 \mathrm{~N}$ at $350{ }^{\circ} \mathrm{C}$.

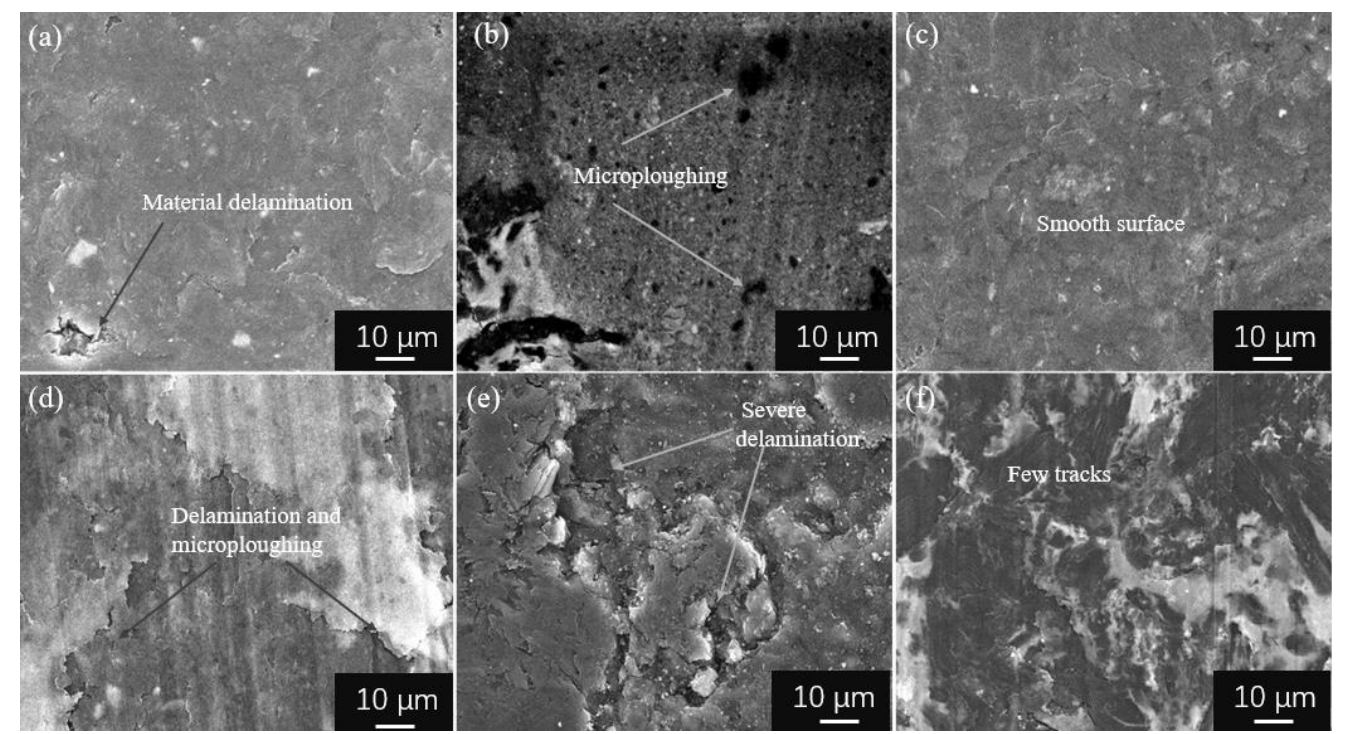

Figure 5. SEM micrographs of wear tracks of Non-IG (a), Resin-IG (b), and Metal-IG (c) under a load of $60 \mathrm{~N}$ at $25^{\circ} \mathrm{C}$. The wear tracks of Non-IG (d), Resin-IG (e), and Metal-IG (f) under a load of $60 \mathrm{~N}$ at $350{ }^{\circ} \mathrm{C}$.

\subsection{Wear Mechanism}

As shown in Figure 5a, the material delamination will happen on the surface of NonIG. At higher temperatures, there is not only material delamination, but there are many micro ploughs (Figure 5d) For Resin-IG in Figure 5b, delamination and micro ploughs are obviously obtained at room temperature, and the severe delamination further occurs when the temperature is higher (Figure 5e) [34,35]. At high friction temperature, the physically adsorbed water vapor from graphite surfaces is prone to being desorbed and cannot improve lubrication for graphite [14,32]. The Metal-IG has much better anti-wear properties at both room temperature (Figure 5c) and high temperature (Figure 5f). The worn surface is smooth without many scratches. For the steel ball sliding against the Non-IG, Resin-IG, and Metal-IG in Figure 6, there is a transferred film on the steel ball that slides against the impregnated graphite for friction and wear reduction. 


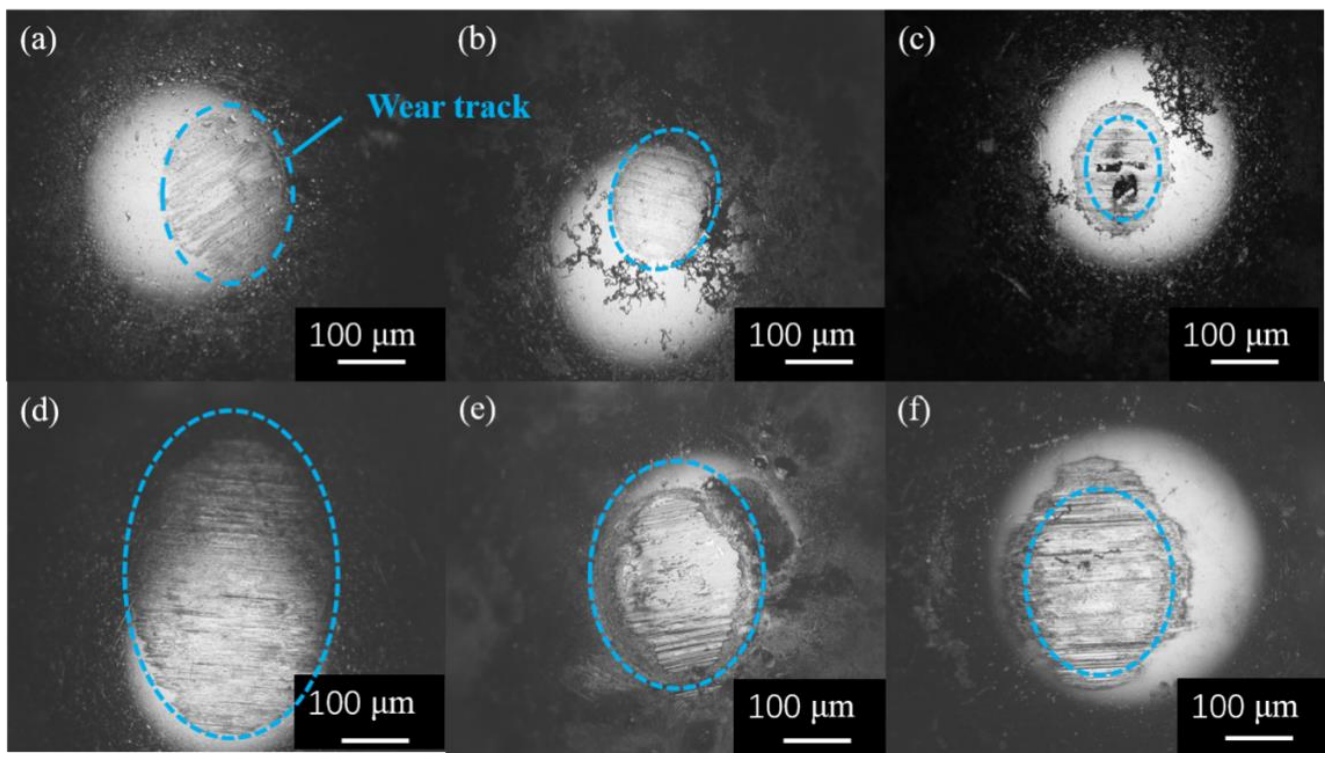

Figure 6. Optical micrographs of the ball scars sliding against Non-IG (a), Resin-IG (b), and Metal-IG (c) under a load of $60 \mathrm{~N}$ at $25^{\circ} \mathrm{C}$. The ball scars sliding against Non-IG (d), Resin-IG (e), and Metal-IG (f) under a load of $60 \mathrm{~N}$ at $350{ }^{\circ} \mathrm{C}$.

The Raman spectra of the initial graphite materials and corresponding wear areas are shown in Figure 7. The spectrum of the Non-IG has two typical characteristic peaks. They are, respectively, $D$ peak at $1350 \mathrm{~cm}^{-1}$ and $G$ peak at $1580 \mathrm{~cm}^{-1}$. The $G$ peak corresponds to the bond stretching of in plane vibration of $\mathrm{sp} 2$ atoms and reflects the order structure of graphite. The D peak is attributed to disorders in graphite, and the intensity ratio of ID/IG can represent the disorder degree in graphite materials shown in Figure 7. As shown in Figure $7 \mathrm{a}-\mathrm{c}$, the structure of the Non-IG displays a high degree of disorder because there is higher intensity of the D peak than that of the G peak and the value of ID/IG is 1.12. There is little change for the structure of Non-IG after friction (ID/IG $\sim 1.10$ at $20 \mathrm{~N}, \sim 1.07$ at $60 \mathrm{~N}$ ). In contrast, the value of ID/IG for Resin-IG changes from 1.13 at the start to a much lower value ( $\sim 1.04$ at $20 \mathrm{~N}$ and $\sim 1.05$ at $60 \mathrm{~N})$ shown in Figure $7 \mathrm{~d}-\mathrm{f}$, meaning that the graphite structure changes to be in order during friction. For Metal-IG, the value of ID/IG is a little higher (1.62) because of the process of impregnating antinomy [36]. With the increase in load, the value for Metal-IG decreases gradually, shown in Figure 7g-k. Specifically, the value of ID/IG is much lower (0.98) under the friction load of $140 \mathrm{~N}$ as well as at high temperature $\left(350^{\circ} \mathrm{C}\right)$ (Figure $\left.7 \mathrm{l}\right)$. Furthermore, there is much wear debris on the ball surface sliding against the Non-IG shown in Figure 8, whereas the steel ball against the Resin-IG shows uniform shallow grooves with a little material spalling and crushing at high temperature. The ball scar for Metal-IG shows little debris and a smooth surface. The C, Si, and $\mathrm{Sb}$ components from Metal-IG are also detected in the wear scar, which confirms that components of metal-impregnated graphite transferred to the steel ball. In addition, the $\mathrm{O}$ content of the friction pair of Non-IG is higher than those of Metal-IG and Resin-IG, which indicates that the oxidation resistance of the Non-IG is worst, because more open pores in the matrix provide a large number of oxygen channels. The impregnated components could interact with graphite during the friction process, including physical and chemical interactions, and these interactions are beneficial to the formation of a steady and complete transfer film [14], which provides efficient lubrication for the resin/graphite composite. It is also found the additives in the graphite could interact with the graphite to make the films stable $[32,37,38]$. In high-temperature environments, oxygen molecules penetrate from the surface into the matrix through these channels [39]. The EDS results show that there are obvious carbon and oxide components on the steel balls, because a transferred film of graphite and surface oxidation are generated during friction. Finally, a mechanically mixed layer of iron oxide compound and graphite transfer film is formed. According to 
the XPS results shown in Figure 9, the Sb and C components are from the tribopart of Metal-IG (Figure 9a-c), and the characteristic peak is from the steel substrate (Figure 9d). Furthermore, there is obvious $\mathrm{Sb}_{2} \mathrm{O}_{3}($ at $530 \mathrm{eV})$ and $\mathrm{Sb}_{2} \mathrm{O}_{5}($ at $531 \mathrm{eV})$ because of frictioninduced oxidation shown in Figure 9c, which also means the oxidation of metal on the transfer film during the friction. $\mathrm{Sb}_{2} \mathrm{O}_{3}$ is easy to form a transfer film between the friction pairs to reduce wear and avoid direct contact; it starts to form at approximately $250{ }^{\circ} \mathrm{C}$, and it has a great self-lubricating property [40]. Many previous studies use the $\mathrm{Sb}_{2} \mathrm{O}_{3}$ as the lubricant components for its outstanding properties [41]. The slight oxidation is beneficial for reduction of the friction and wear due to the self-lubrication oxide layer $[39,42]$.
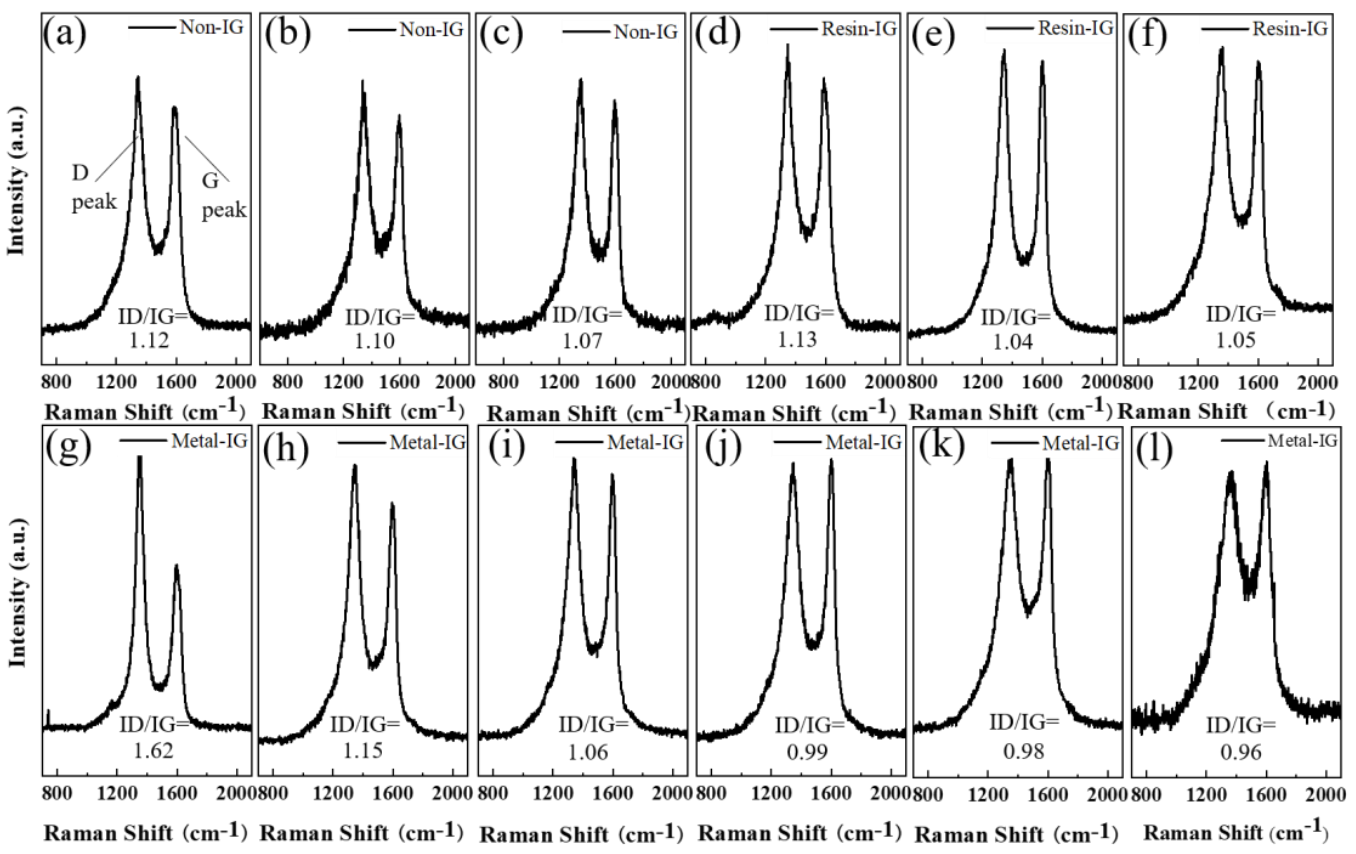

Figure 7. Raman spectra of Non-IG surface (a) and corresponding rubbing surfaces under a load of $20 \mathrm{~N}$ (b) and $60 \mathrm{~N}$ (c) at $25^{\circ} \mathrm{C}$; Raman spectra of Resin-IG surface (d) and corresponding rubbing surfaces under a load of $20 \mathrm{~N}$ (e) and $60 \mathrm{~N}$ (f) at $25^{\circ} \mathrm{C}$; Raman spectra of Metal-IG surface (g) and corresponding rubbing surfaces under a load of $20 \mathrm{~N}(\mathbf{h}), 60 \mathrm{~N}(\mathbf{i}), 100 \mathrm{~N}(\mathbf{j}), 140 \mathrm{~N}(\mathbf{k})$ at $25^{\circ} \mathrm{C}$, and $60 \mathrm{~N}(\mathbf{1})$ at $350{ }^{\circ} \mathrm{C}$. 

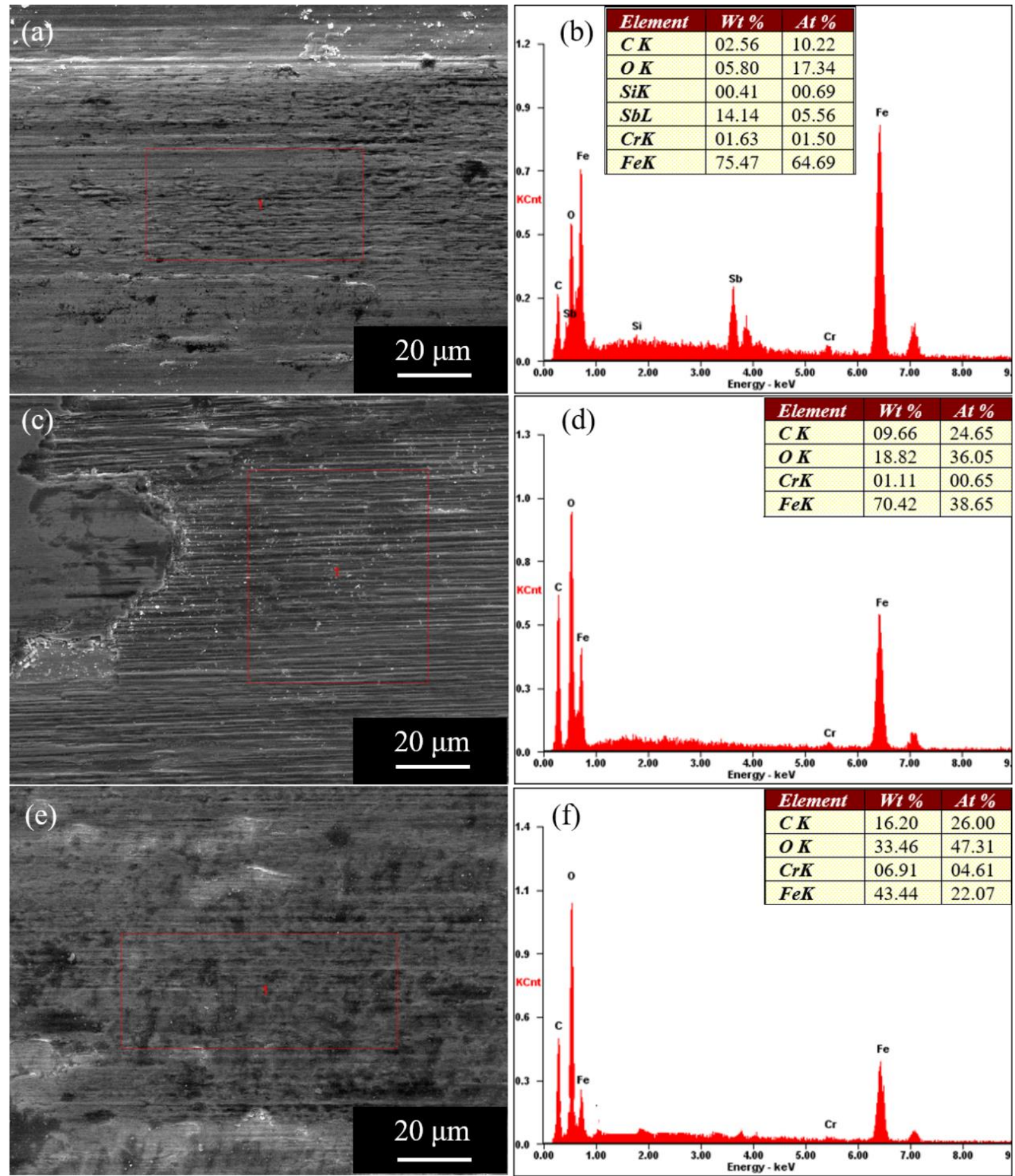

Figure 8. SEM micrographs and EDS maps of the wear scars of steel balls sliding against Metal-IG $(\mathbf{a}, \mathbf{b})$, Resin-IG (c,d), and Non-IG (e,f) under a load of $60 \mathrm{~N}$ at $350{ }^{\circ} \mathrm{C}$. 

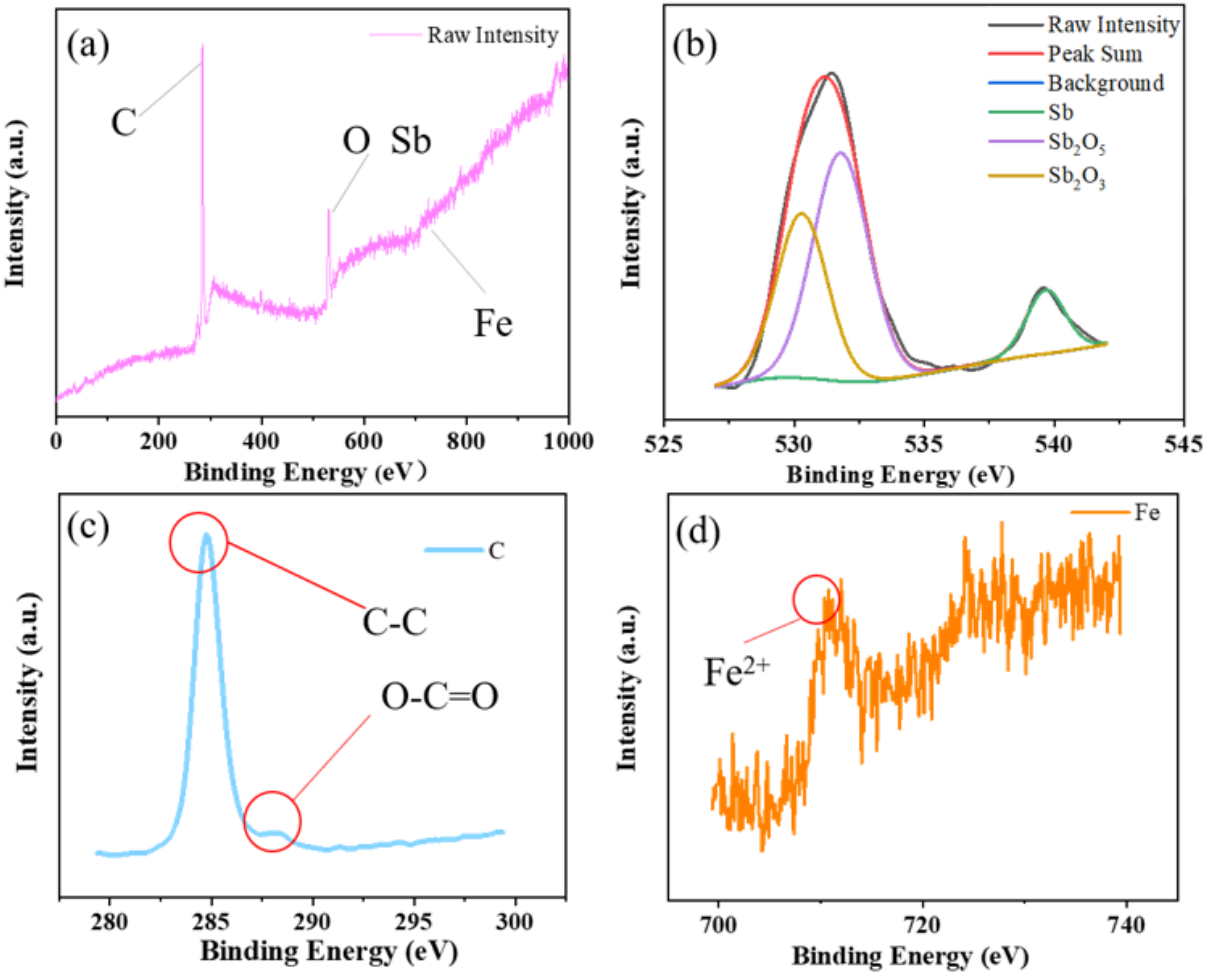

Figure 9. The XPS of the valence band energy region on the ball scars against Metal-IG at $350{ }^{\circ} \mathrm{C}(\mathbf{a})$; high-resolution XPS spectra of Sb 3d (b), C 1s (c), and Fe 2p (d).

\section{Conclusions}

The tribological properties of impregnated graphite are investigated at high temperature and high load in comparison with non-impregnated graphite. The Metal-IG composite displays the best properties, and the COF can be reduced by approximately $20 \%$ compared with those of Non-IG at high temperature $\left(350^{\circ} \mathrm{C}\right)$. Specifically, Metal-IG has the highest carrying capacity of over $100 \mathrm{~N}$ (325.9 MPa). The tribological properties of Resin-IG are better than those of Non-IG, but both gradually become unstable and worse under harsh conditions. Compared with Non-IG, the Metal-IG and Resin-IG can reduce the wear depth by $60 \%$ and $80 \%$, respectively. The impregnated materials (metal or resin) can enhance the hardness of the graphite matrix and improve the formation of graphite tribofilm on the counterpart surfaces. Friction-induced structural ordering of graphite and slight oxidation of metal in the formed mechanically mixed layer is also beneficial for the friction and wear reduction.

Author Contributions: Conceptualization, J.Z.; methodology, J.Z.; validation, D.L., Y.G. and R.Z.; formal analysis, R.M.; investigation, J.Z.; resources, S.L.; data curation, Y.L.; writing—original draft preparation, Y.L.; writing—review and editing, J.Z.; visualization, Y.W.; supervision, Y.S.; project administration, S.L.; funding acquisition, S.L. All authors have read and agreed to the published version of the manuscript.

Funding: This resarch was funded by the National Natural Science Foundation of China (Grant No. 51905027), the National Key R\&D Program of China (2018YFB-2000801), the Fundamental Research Funds for the Central Universities (BUCTRC201908), the Tribology Science Fund of State Key Laboratory of Tribology (SKLTKF18A02), and the Opening Foundation of State Key Laboratory of Organic-Inorganic Composites, Beijing University of Chemical Technology (oic-202101012). The APC was funded by the National Key R\&D Program of China (2018YFB-2000801).

Acknowledgments: The authors are thankful for Idiris. mehamud. aliyi's suggestions and revision of this work.

Conflicts of Interest: The authors declare no conflict of interest. 


\section{References}

1. Holmberg, K.; Erdemir, A. Influence of tribology on global energy consumption, costs and emissions. Friction 2017, 5, 263-284. [CrossRef]

2. Zhao, J.; Huang, Y.; He, Y.; Shi, Y. Nanolubricant additives: A review. Friction 2021, 9, 891-917. [CrossRef]

3. Zhao, J.; Li, Y.; He, Y.; Luo, J. In Situ Green Synthesis of the New Sandwichlike Nanostructure of Mn3O4/Graphene as Lubricant Additives. Acs Appl. Mater. Int. 2019, 11, 36931-36938. [CrossRef]

4. Zhang, G.; Chen, G.; Zhao, W.; Yan, X.; Zhang, Y. An Experimental Test on a Cryogenic High-Speed Hydrodynamic Non-Contact Mechanical Seal. Tribol Lett. 2017, 65, 65-80. [CrossRef]

5. Zhao, J.; Mao, J.; Li, Y.; He, Y.; Luo, J. Friction-induced nano-structural evolution of graphene as a lubrication additive. Appl. Surf. Sci. 2018, 434, 21-27. [CrossRef]

6. Leonardi, M.; Alemani, M.; Straffelini, G.; Gialanella, S. A pin-on-disc study on the dry sliding behavior of a Cu-free friction material containing different types of natural graphite. Wear 2020, 203, 442-443. [CrossRef]

7. Jradi, K.; Schmitt, M.; Bistac, S. Surface modifications induced by the friction of graphites against steel. Appl. Surf. Sci. 2009, 255, 4219-4224. [CrossRef]

8. Hirani, H.; Goilkar, S.S. Formation of transfer layer and its effect on friction and wear of carbon-graphite face seal under dry, water and steam environments. Wear 2009, 266, 1141-1154. [CrossRef]

9. Chen, G.X.; Li, F.X.; Dong, L.; Zhu, M.H.; Zhou, Z.R. Friction and wear behaviour of stainless steel rubbing against copperimpregnated metallized carbon. Tribol. Int. 2009, 42, 934-939. [CrossRef]

10. Jia, Q.; Yuan, X.; Zhang, G.; Dong, G.; Zhao, W. Dry friction and wear characteristics of impregnated graphite in a corrosive environment. Chin. J. Mech. Eng. 2014, 27, 965-971. [CrossRef]

11. Lafon-Placette, S.; Delbé, K.; Denape, J.; Ferrato, M. Tribological characterization of silicon carbide and carbon materials. J. Eur. Ceram. 2015, 35, 1147-1159. [CrossRef]

12. Li, J. The effect of the addition of graphite on tribological properties of glass fibre-reinforced polyimide composites. Proc. Inst. Mech. Eng. Part J J. Eng. Tribol. 2009, 224, 279-284. [CrossRef]

13. Zhang, G.; Liu, Y.; Guo, F.; Liu, X.; Wang, Y. Friction Characteristics of Impregnated and Non-Impregnated Graphite against Cemented Carbide under Water Lubrication. J. Mater. Sci. Technol. 2017, 33, 1203-1209. [CrossRef]

14. Zhu, Z.; Bai, S.; Wu, J.; Xu, L.; Li, T.; Ren, Y.; Liu, C. Friction and Wear Behavior of Resin/Graphite Composite under Dry Sliding. J. Mater. Sci. Technol. 2015, 31, 325-330. [CrossRef]

15. Fei, J.; Li, H.; Huang, J.; Fu, Y. S tudy on the friction and wear performance of carbon fabric/phenolic composites under oil lubricated conditions. Tribol. Int. 2017, 56, 30-37. [CrossRef]

16. Sekiguchi, S.; Suzuki, H.; van Ryper, R.G.; Ritchey, D.J. Development of a new seal material to reduce energy losses in vehicle transmissions. Seal. Technol. 2009, 11, 8-11. [CrossRef]

17. Wang, J.; Jia, Q.; Yuan, X.; Wang, S. Experimental study on friction and wear behaviour of amorphous carbon coatings for mechanical seals in cryogenic environment. Appl. Surf. Sci. 2012, 258, 9531-9535. [CrossRef]

18. Li, J.; Zhang, L.; Xiao, J.; Zhou, K. Sliding wear behavior of copper-based composites reinforced with graphene nanosheets and graphite. Trans. Nonferr. Met. Soc. China 2015, 25, 3354-3362. [CrossRef]

19. Ma, W.; Lu, J. Effect of Sliding Speed on Surface Modification and Tribological Behavior of Copper-Graphite Composite. Tribol Lett. 2010, 41, 363-370. [CrossRef]

20. Su, L.; Gao, F.; Han, X.; Chen, J. Effect of copper powder third body on tribological property of copper-based friction materials. Tribol. Int. 2015, 90, 420-425. [CrossRef]

21. Wang, J.; Zhang, R.; Xu, J.; Wu, C.; Chen, P. Effect of the content of ball-milled expanded graphite on the bending and tribological properties of copper-graphite composites. Mater. Des. 2013, 47, 667-671. [CrossRef]

22. Cao, H.M.; Zhou, X.; Li, X.Y.; Lu, K. Friction mechanism in the running-in stage of copper: From plastic deformation to delamination and oxidation. Tribol. Int. 2017, 115, 3-7. [CrossRef]

23. Wang, Y.; Gao, Y.; Sun, L.; Li, Y.; Zheng, B.; Zhai, W. Effect of physical properties of Cu-Ni-graphite composites on tribological characteristics by grey correlation analysis. Results Phys. 2017, 7, 263-271. [CrossRef]

24. Williams, J.A.; Morris, J.H.; Ball, A. The effect of transfer layers on the surface contact and wear of carbon-graphite materials. Tribol. Int. 1997, 9, 663-676. [CrossRef]

25. Jin, K.; Qiao, Z.; Zhu, S.; Cheng, J.; Yin, B.; Yang, J. Friction and wear properties and mechanism of bronze-Cr-Ag composites under dry-sliding conditions. Tribol. Int. 2016, 96, 132-140. [CrossRef]

26. Engqvist, H.; Hogberg, H.; Botton, G.A.; Ederyd, S.; Axen, N. Tribofilm formation on cemented carbides in dry sliding conformal contact. Wear 2000, 239, 219-228. [CrossRef]

27. Hokao, M.; Hironaka, S.; Suda, Y.; Yamamoto, Y. Friction and wear properties of graphiter glassy carbon composites. Wear 2000, 237, 54-62. [CrossRef]

28. Zhang, G.; Liu, Y.; Wang, Y.; Guo, F.; Liu, X.; Wang, Y. Wear behavior of WC-Ni sliding against graphite under water lubrication. J. Mater. Sci. Technol. 2017, 33, 1346-1352. [CrossRef]

29. Guo, F.; Tian, Y.; Liu, Y.; Wang, Y. Ultralow friction between cemented carbide and graphite in water using three-step ring-on-ring friction test. Wear 2016, 352, 54-64. [CrossRef] 
30. Cui, G.; Bi, Q.; Zhu, S.; Yang, J.; Liu, W. Tribological behavior of Cu-6Sn-6Zn-3Pb under sea water, distilled water and dry-sliding conditions. Tribol. Int. 2012, 55, 126-134. [CrossRef]

31. Shankar, S.; Praveenkumar, G.; Krishnakumar, P. Experimental study on frictional characteristics of tungsten carbide versus carbon as mechanical seals under dry and eco-friendly lubrications. Int. J. Refract. Met. Hard Mater. 2016, 54, 39-45. [CrossRef]

32. Zhao, J.; Li, Q.; Li, S.; Li, S.; Chen, G.; Liu, X.; He, Y.; Luo, J. Influence of a carbon-based tribofilm induced by the friction temperature on the tribological properties of impregnated graphite sliding against a cemented carbide. Friction 2020, 9, 686-696. [CrossRef]

33. Yang, C.; Hui, H.; Huang, S. Theoretical and experimental study on sealing performance of a novel ultra-highpressure bursting disc. Proc. Inst. Mech. Eng. Part J J. Eng. Tribol. 2020, 22, 1-7.

34. Heinz, K.; Gahr, Z. Microstructure and Wear of Materials; Elsevier Science Publishers: Amsterdam, The Netherlands, 1987.

35. Fischer, A.; Dudzinski, W.; Gleising, B.; Stemmer, P. Analyzing Mild- and Ultra-Mild Sliding Wear of Metallic Materials by Transmission Electron Microscopy. In Advanced Analytical Methods in Tribology; Springer: Berlin, Germany, 2018 ; pp. $29-59$.

36. Xu, A.; Xia, Q.; Zhang, S.; Duan, H.; Yan, Y.; Wu, S. Ultrahigh Rate Performance of Hollow Antimony Nanoparticles Impregnated in Open Carbon Boxes, for Sodium-Ion Battery under Elevated Temperature. Adv. Sci. News. 2019, 15, 1903521. [CrossRef]

37. Langlade, C.; Fayeulle, S.; Olierb, R. Role of additive in the physico-chemistry of graphite-based transfer films. Thin Solid Film. 1994, 237, 38-47. [CrossRef]

38. Wang, Q.; He, M.; He, Y.; Hu, Y.; Liu, Q. Microstructure and Tribological Properties of Graphite/Antimony Composites for Mechanical Seal. Asian J. Chem. 2014, 26, 5657-5662. [CrossRef]

39. Liu, R.; Cheng, K.; Chen, J.; Xiong, X.; Lin, X. Friction and wear properties of high temperature and low temperature sintered copper-graphite brushes at different ambient temperatures. J Mater. Res. Technol. 2020, 9, 7288-7296. [CrossRef]

40. Lee, W.K.; Rhee, T.H.; Kim, H.S.; Jang, H. Effects of Antimony Trisulfide (Sb2S3) on Sliding Friction of Automotive Brake Friction Materials. Met. Mater. Int. 2013, 5, 1101-1107. [CrossRef]

41. Wang, B.; Gao, K.; Chang, Q.; Berman, D.; Tian, Y. Magnesium Silicate Hydroxide-MoS2-Sb2O3 Coating Nanomaterials for High-Temperature Superlubricity. ACS. Appl. Nano. Mater. 2021, 4, 7097-7106. [CrossRef]

42. Gomes, J.R.; Miranda, A.S.; Rui, F.S.; Vieira, J.M. Tribooxidational Effects on Friction and Wear Behavior of Silicon Nitride/Tool Steel and Silicon Nitride/Gray Cast Iron Contacts. J. Am. Ceram. Soc. 2020, 4, 953-960. 